Article

\title{
Polyyne-Enriched Extract from Oplopanax elatus Significantly Ameliorates the Progression of Colon Carcinogenesis in $A p c^{\mathrm{Min} /+}$ Mice
}

\author{
Xin Qiao ${ }^{1}$, Wei Sun ${ }^{1}$, Chongzhi Wang ${ }^{2}$, Li Zhang ${ }^{1}$, Ping Li ${ }^{1}$, Xiaodong Wen ${ }^{1, *}$, Jie Yang ${ }^{1, *}$ and \\ Chunsu Yuan ${ }^{2}$ \\ 1 State Key Laboratory of Natural Medicines, China Pharmaceutical University, Nanjing 211198, China; \\ xinqiao@stu.cpu.edu.cn (X.Q.); cpusunw6688@126.com (W.S.); zhangli@stu.cpu.edu.cn (L.Z.); \\ liping2004@126.com (P.L.) \\ 2 Tang Center for Herbal Medicine Research and Department of Anesthesia \& Critical Care, The Pritzker \\ School of Medicine, The University of Chicago, Chicago, IL 60601, USA; czwang@dacc.uchicago.edu (C.W.); \\ CYuan@dacc.uchicago.edu (C.Y.) \\ * Correspondence: xiaodongwen@cpu.edu.cn (X.W.); cpusyj@163.com (J.Y.); Tel.: +86-25-8618-5102 (X.W.)
}

Received: 30 July 2017; Accepted: 19 September 2017; Published: 22 September 2017

\begin{abstract}
Colorectal cancer (CRC) is the third most common cancer in the world. Oplopanax elatus is widely used in traditional medicine. However, little is known about its pharmacological effects and bioactive compounds. We evaluated the effects of the polyyne-enriched extract from O. elatus (PEO) on the progression of colon carcinogenesis in $\mathrm{Apc}^{\mathrm{Min} /+}$ mice. In addition, these effects were also investigated in HCT116 and SW480 cells. After PEO oral administration ( $0.2 \%$ diet) for 12 weeks, PEO significantly improved body weight changes and reduced the tumor burden and tumor multiplicity compared with the untreated mice. Meanwhile, western blot and immunohistochemistry results showed PEO significantly reduced the expression of $\beta$-catenin and cyclinD1 in both small intestine and the colon tissues compared with the untreated mice. In addition, PEO treatment significant decreased the cell viability in both HCT116 and SW480 cell lines. It also decreased the levels of $\beta$-catenin, cyclinD1, c-myc and p-GSK-3 $\beta$ in HCT116 and SW480 cells at $25 \mu \mathrm{M}$. These results indicate that $\mathrm{PEO}$ may have potential value in prevention of colon cancer by down-regulating Wnt-related protein.
\end{abstract}

Keywords: PEO; colorectal cancer; Wnt/ $\beta$-catenin signaling

\section{Introduction}

Colorectal cancer (CRC) is the third most commonly diagnosed cancer and the fourth leading cause of cancer deaths around the world [1]. In 2017, it is estimated that 135,430 new CRC cases and 50,260 deaths will occur in the United States [2]. The current therapeutic approaches for CRC are mainly surgery, chemotherapy, radiotherapy, and immunotherapy. However, these strategies are often limited by severe side effects, genetic mutations and dose-limiting toxicity [3-7]. Meanwhile, it has been demonstrated that numerous natural products have significant anticancer effects [8]. Therefore, discovering new and less toxic compounds from herbal medicine may shed new light on the development of anticancer agents, which can selectively kill cancer cells or enhance the effects of existing chemotherapeutic agents [9].

Oplopanax elatus (Nakai) Nakai (O. elatus), grows throughout eastern Asia, including northeast China, Korea and the far east of Russia [10,11]. The plant is a member of the family Araliaceae, the same family as American ginseng and is, therefore, occasionally referred to as "Alaskan ginseng" or "Pacific ginseng", although they are in different genera [12]. It has been long used to treat many diseases such 
as arthritis, diabetes mellitus, rheumatism, neurasthenia, and cardiovascular diseases [13,14]. However, compared with the extensive researches on other plants in Araliaceae, such as Ginseng, Eleuther ococcus and Aralia [13,15], comparatively little is known about the pharmacological effects and bioactive compounds of $O$. elatus. Phytochemical studies have revealed there are many kinds of components in O. elatus, such as the essensial oil, saponins, phenolic glycosides and polyynes [16]. Recently, increasing evidences have suggested polyynes have significant anti-tumor activities [17]. Facarindiol (FAD), one of polyynes isolated from Oplopanax horridus, can inhibit tumor growth inhibiting proteasome function and increasing accumulation of ubiquitinated proteins [18]. Similarly, oplopandiol (OPD) also has the pharmacological effects of activating endoplasmic reticulum stress and regulating $\mathrm{BH} 3$ family proteins to promote apoptosis of colon cancer cells [18]. Our previous studies have showed FAD and OPD are two main polyynes compounds of O. elatus and they are rapidly absorbted in vivo [19]. Based on this background, we hypothesized that polyyne-enriched extract from O. elatus (PEO) could ameliorate the progression of colon carcinogenesis. In this study, we aimed to investigate whether polyyne-enriched extract from $O$. elatus can improve the progression of colon carcinogenesis in $A p c^{\mathrm{Min} /+}$ mice. In addition, these effects were also investigated in HCT116 and SW480 cells.

\section{Results}

\subsection{Effects of the PEO in Apc $\mathrm{Min}^{\mathrm{+}+}$ Mice}

2.1.1. PEO Treatment Improved the Body Weight and Stool Bleeding in $A p c^{\mathrm{Min} /+}$ Mice

The body weight changes in different experimental groups are shown in Figure 1A. Compared with the control group, the model group had significant weight gain beginning on 6 week whereas PEO groups significantly reduced the body weight gain. In addition, the model group gradually had gross bleeding while these bleeding symptoms were greatly improved in the PEO group (Figure 1B), suggesting the reduced pathological problems.

A

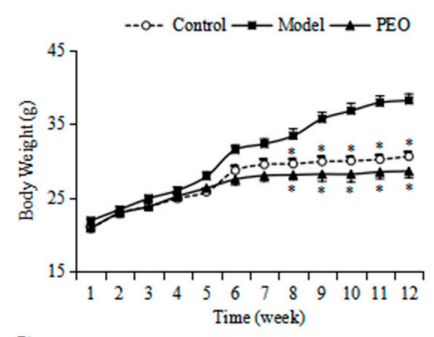

C

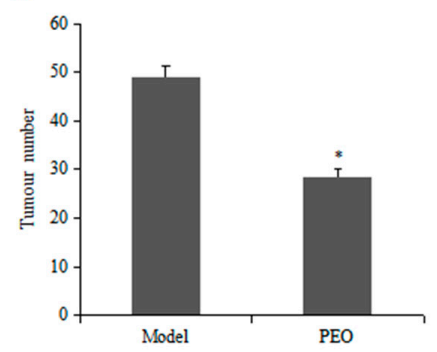

B

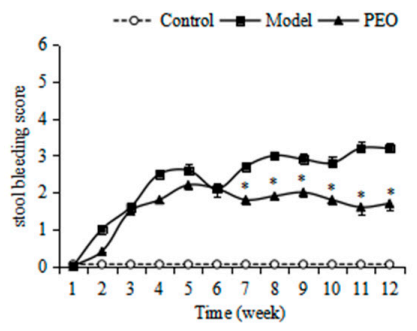

D

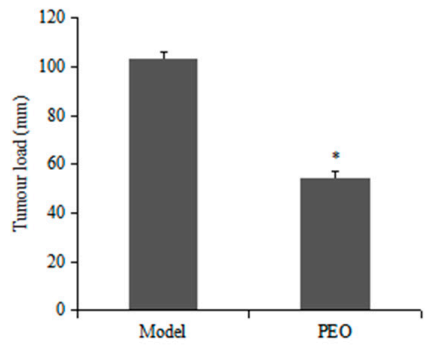

Figure 1. The effects of PEO on mouse body weight changes is shown in (A); The PEO attenuated stool bleeding score in $A p c^{\mathrm{Min} /+}$ mice (B); PEO treatment reduced tumor counts (C) and tumor load (D) in $A p c^{\mathrm{Min} /+}$ mice. (Data represent the means $\pm \mathrm{SE}$ of independent experiments. ${ }^{*} p<0.05$ relative to model group). 


\subsubsection{PEO Feeding Prevents Intestinal Tumorigenesis in $A p c^{\mathrm{Min} /+}$ Mice}

The morphological observation results showed that no adenomatoid lesions in the control group (Figure 2A), while in the model group there were more than 40 adenomatoid lesions in the whole intestine (Figures $1 \mathrm{C}$ and 2B). This finding is comparable with that of previous publications in $\mathrm{Apc}$ Min/+ mice [20]. The tumors in mice treated with PEO fortified diet were visibly less than those observed in mice treated with high fat diet (Figures $1 C$ and $2 B, C$ ). In addition, the reduction in overall tumor burden was obvious in mice treated with PEO (Figure 1D).

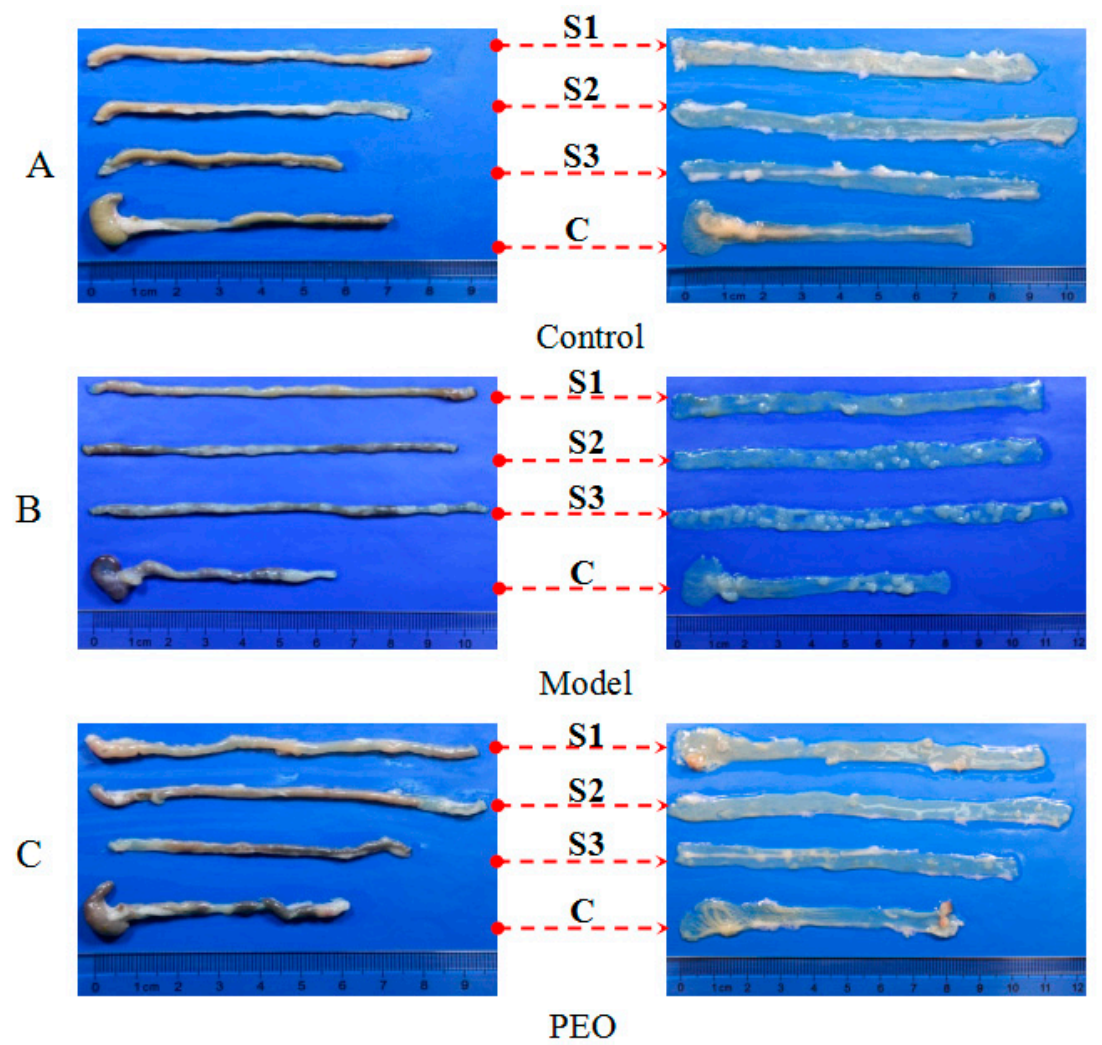

Figure 2. The appearance and morphology of the proximal (S1), middle (S2) and distal (S3) of the small intestine and colon (C). (A) Control group; (B) Model group; (C) PEO (0.2\% diet) group.

HE staining was carried out to observe and characterize the histological alterations. As shown in Figure S1A,B, the model group showed severe crypt dysplasia, adenomas, and adenocarcinomas in the colon compared with normal group. Inflammation, leukocyte infiltration into the lumen, nuclear hyperchromasia, nuclear mitosis, and increased nucleus-to cytoplasm ratio were observed in the adenocarcinomas of $\mathrm{Apc}^{\mathrm{Min} /+}$ mice. However, administering PEO greatly reduced these dysplastic changes in both intestine and colon slides (Figure S1C). Taken together, these results demonstrate that dietary feeding of PEO effectively suppresses tumor growth in $\mathrm{Apc}^{\mathrm{Min} /+}$ mice.

\subsubsection{PEO Decreased the Expression of $\beta$-Catenin and CyclinD1 in $A p c^{\mathrm{Min} /+}$ Mice}

Activation of the Wnt/ $\beta$-catenin signaling pathway was shown to be one of the primary drivers of CRC development [21]. In $A p c^{\mathrm{Min} /+}$ mice, the mutations of Apc gene could activate Wnt/ $\beta$-catenin signaling by preventing $\beta$-catenin degradation, which results in nuclear translocation of stabilized $\beta$-catenin and activate target gene transcription. In our study, the results of western blot and immunochemistry showed the expression of $\beta$-catenin was upregulated both in the small intestine and colon tissues in the $A p c^{\mathrm{Min} /+}$ mice, while PEO-treated could significantly reduce its expression (Figures $3 \mathrm{~A}$ and $4 \mathrm{~A}-\mathrm{C}$ ). 


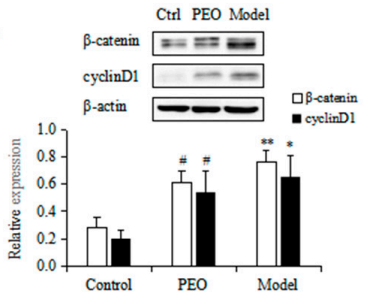

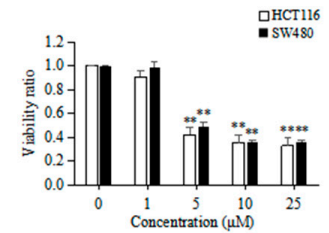

C

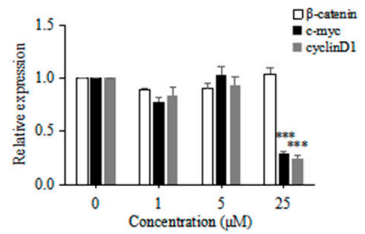

$\mathbf{E}$

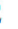
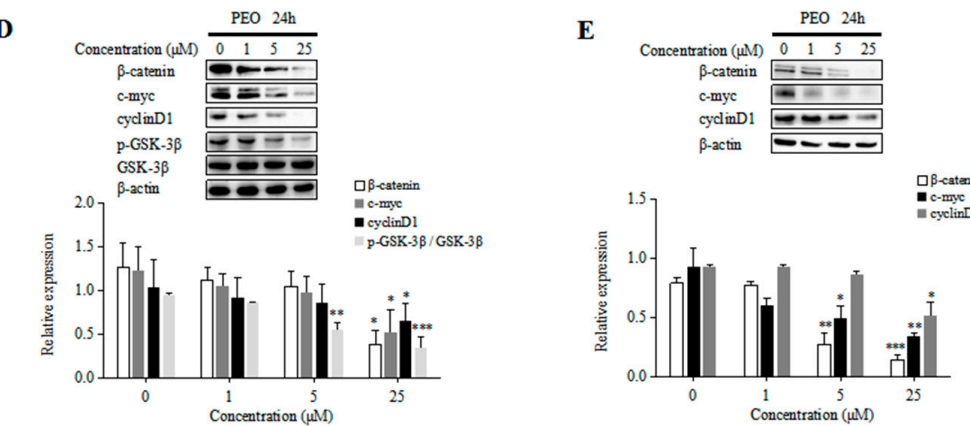

Figure 3. (A) PEO inhibits the expression of $\beta$-catenin and cyclinD1 in intestinal tissues of animals; (B) Anti-proliferative effects of different concentrations of PEO on the growth of HCT116 and SW480 cells; (C) PEO inhibits the mRNA expression of c-myc and cyclinD1 in HCT116 cells; (D) PEO inhibits the expression of $\beta$-catenin, c-myc, cyclinD1 and p-GSK-3 $\beta$ in HCT116 cells; (E) PEO inhibits the expression of $\beta$-catenin, c-myc and cyclinD1 in SW480 cells. Density values were normalized to levels of $\beta$-actin. Data represent the means \pm SE of independent experiments. ${ }^{\#} p<0.05$ relative to model group, ${ }^{*} p<0.05,{ }^{* *} p<0.01,{ }^{* * *} p<0.001$ relative to control group.

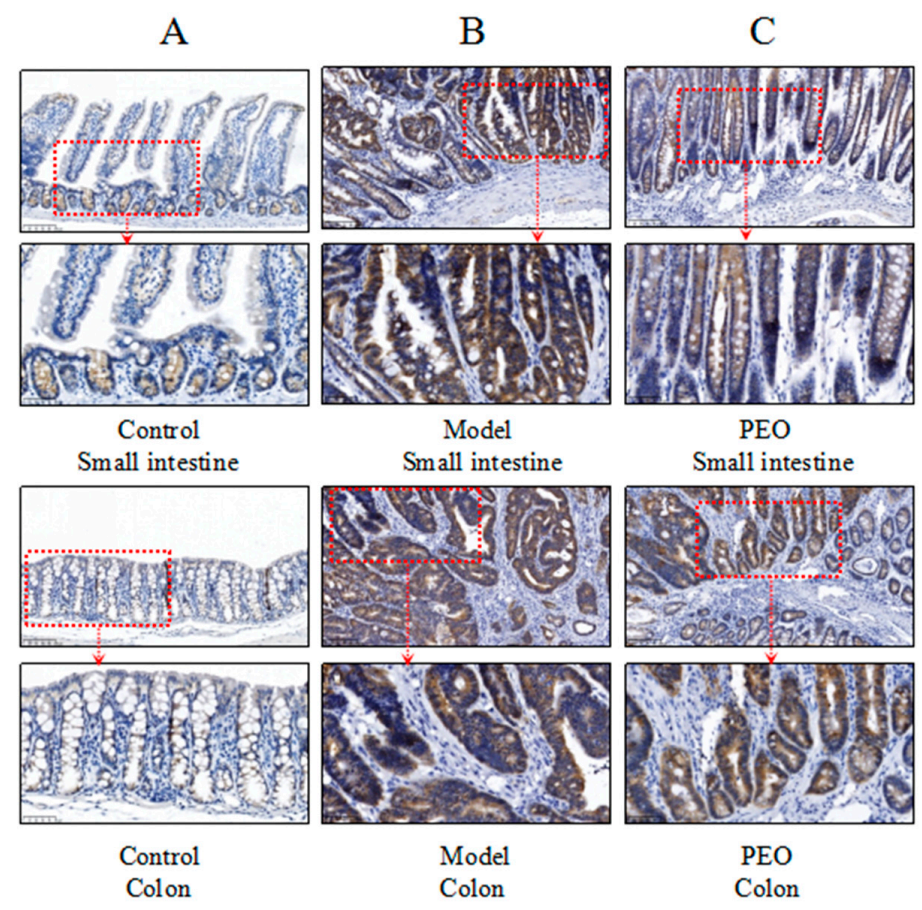

Figure 4. The expression of $\beta$-catenin in control group (A); model group (B); PEO (0.2\% diet) group (C) was analyzed by immunohistochemistry, bar $=100 \mu \mathrm{m}(20 \mu \mathrm{m} \times 5)$ and bar $=50 \mu \mathrm{m}(10 \mu \mathrm{m} \times 5)$. Samples were scanned by Nano Zoomer 2.0 HT and pictures were obtained from NDP. View 2 (Hamamatsu Photonics K.K., Hamamatsu, Japan). 
In addition, the expression of cyclinD1 was also increased in $A p c^{\mathrm{Min} /+}$ mice. In contrast, the level of cyclinD1 was significantly decreased after PEO treatment (Figure 3A), indicating PEO might prevents intestinal tumorigenesis in $A p c^{\mathrm{Min} /+}$ mice via Wnt/ $\beta$-catenin signaling pathway.

\subsection{Effects of the PEO in HCT116 and SW480 Cells}

\subsubsection{Anti-Proliferative Effects of PEO in Colon Cancer Cells}

The cytotoxicity of PEO against HCT116 and SW480 cells were measured using MTT assay. Both HCT116 and SW480 cell lines were treated with various concentrations of PEO $(1,5,10,25 \mu \mathrm{M})$. The cell viability was observed to be reduced in a dose-dependent manner following PEO treatment. The $\mathrm{IC}_{50}$ of PEO in SW480 was $3.03 \mu \mathrm{M}$, while in HCT116 was only $2.84 \mu \mathrm{M}$ (Figure 3B), demonstrating the ability of PEO of preventing colon carcinogenesis in vitro.

\subsubsection{PEO Decreased the Expression of $\beta$-Catenin, CyclinD1, C-myc and P-GSK-3 $\beta$ in HCT116 and SW480 Cells}

As PEO could reduce the expressions of $\beta$-catenin and cyclinD1 in vivo, we examined the effect of PEO on the expression of these proteins in vitro. As shown in Figure 3D, PEO treatment decreased the protein levels of $\beta$-catenin, cyclinD1, c-myc and p-GSK-3 $\beta$ in HCT116 cells at $25 \mu \mathrm{M}$. In accordance with this, PEO treatment also down-regulated the protein levels of $\beta$-catenin, cyclinD1 and c-myc at $25 \mu \mathrm{M}$ in SW480 cells (Figure 3E). To further investigate the mediation of $\beta$-catenin, cyclinD1, c-myc reduction at protein level or mRNA level, mRNA of $\beta$-catenin, cyclinD1, c-myc was quantified in HCT116 cells. In accordance with our western blot results, PEO treatment at $25 \mu \mathrm{M}$ decreased the mRNA levels of cyclinD1 and c-myc. However, the expression of $\beta$-catenin mRNA was not altered upon PEO treatment (Figure 3C).

\section{Discussion}

O. elatus has been used for treating neurasthenia, hypoiesis, cardiovascular diseases, diabetes and rheumatism in Russian medicine and Traditional Chinese medicine. However, its bioactive compounds are still not clarified. In this study, we prepared the polyyne-enriched extract from O. elatus (PEO) and evaluated its effect on colon cancer. The chromatogram of the PEO, showed FAD and OPD are two main polyynes in PEO extract. The contents of these two compounds are $24.39 \%$ and $57.90 \%$ in the extract [19]. In addition, UPLC-Q-TOF was used to characteristic the main compounds in PEO extract. As shown in Table S1, 9 peaks were characterized. In order to confirm our hypothesis that polyyne-enriched extract from O. elatus is responsible for the anticancer activities of O. elatus. Apc $\mathrm{Min} /+$ mice, a genetically engineered mouse model that has a mutation in the Apc gene were applied. PEO treated significantly improved the body weight changes and stool bleeding score in $\mathrm{Apc}$ Min/+ mice. Compared with the model group, the tumor numbers were significantly reduced after treatment with PEO for 12 weeks. Furthermore, the cell viability was observed to be reduced in a dose-dependent manner following PEO treatment in HCT116 and SW480 cells. In addition, many reports showed the toxicity of $O$. elatus root is very low [13]. No signs of toxicity were observed in mice after acute oral administration at a dose of 50 (g original material $/ \mathrm{kg}$ ) [22]. The safety of the extract of O. elatus were examined in 14-day in SD rats. There were no significant changes in body and organ weights when the rats were treated with the extract by gavage at 500, 1000, $2000 \mathrm{mg} / \mathrm{kg}$ [23]. In our experiment, the PEO oral administration is about $6 \mathrm{mg}$ per mouse a day. Considering the yield of the extract $(67 \mathrm{~g}$ extract were obtained from $4 \mathrm{~kg}$ crude materials), our dosage is 1.8 (g original material $/ \mathrm{kg}$ ), which is lower than these reported dosages. Taken together, we demonstrated that PEO significantly reduced the progression of carcinogenesis in $A p c^{\mathrm{Min} /+}$ mice.

The Wnt/ $\beta$-catenin signaling pathway controls many biological processes, including cell fate determination, cell proliferation and stem cell maintenance [24]. Many researches have been demonstrated the link between $\mathrm{Wnt} / \beta$-catenin signaling and cancer $[25,26]$. The key regulatory step 
involves the phosphorylation, ubiquitination and subsequent degradation of its down-stream effector protein, $\beta$-catenin, by a dedicated cytoplasmic destruction complex. The core components in this complex are including Axin, Apc and GSK-3 $\beta$. Mutations in any of them will result in cancer [27]. Thus, in $A p c^{\mathrm{Min} /+}$ mice, the mutations of Apc gene could activate Wnt/ $\beta$-catenin signaling by preventing $\beta$-catenin degradation, which results in nuclear translocation of stabilized $\beta$-catenin and activate target gene transcription [28]. Consistent with this, in our study, we find the $\beta$-catenin is highly accumulated in $A p c^{\mathrm{Min} /+}$ mice. At the same time, the expression of cyclinD1 was also increased. In contrast, the level of $\beta$-catenin and cyclinD1 were significantly decreased after PEO treatment in $A p c^{\mathrm{Min} /+}$ mice. Meanwhile, PEO treatment decreased the protein levels of $\beta$-catenin, cyclinD1, c-myc and p-GSK-3 $\beta$ in HCT116 and SW480 cells at $25 \mu \mathrm{M}$. PEO treatment at $25 \mu \mathrm{M}$ also downregulated mRNA levels of cyclinD1 and c-myc in HCT116 cells. However, the expression of $\beta$-catenin mRNA was not altered upon PEO treatment, indicating PEO treatment regulated the expression of $\beta$-catenin at the protein level. All these results suggested PEO ameliorates the progression of colon carcinogenesis partly by the regulation of $\mathrm{Wnt} / \beta$-catenin signaling. In addition, apart from Wnt signaling, many other pathways such as MAPK/PI3K, TGF- $\beta$, TP53 also plays an important roles in the carcinogenesis [29]. Further investigation still needed to study the effects of PEO on these pathways. In summary, using the carcinogenesis $A p c^{\mathrm{Min} /+}$ mouse model, we report that PEO significantly ameliorates tumor initiation and progression. The observed effects were supported by the body weight change and gut tissue histology. Moreover, our works showed that PEO could regulate $W n t / \beta$-catenin signaling in vivo and in vitro, thereby ameliorated colon cancer progression. These findings help us to have a better understanding about the bioactive compounds in O. elatus and its anticancer effect action, contributing to its further application in the prevention of colon cancer.

\section{Materials and Methods}

\subsection{Chemicals, Material and Reagents}

The dried Oplopanax elatus was collected from natural habitat in Jilin, China, and authenticated by Prof. Wen Xiao-Dong, China Pharmaceutical University, Nanjing, China. Antibodies of c-myc, cyclinD1, $\beta$-catenin were purchased from Abcam (Cambridge, UK). Anti-GSK-3 $\beta$ was obtained from Wanleibio (Shenyang, Liaoning, China). Anti-p-GSK-3 $\beta$ was obtained from Santa Cruz Biotechnology (Santa Cruz, CA, USA) and anti- $\beta$-actin was purchased from Beyotime (Nanjing, Jiangsu, China).

\subsection{Preparation of PEO}

The PEO was prepared according to our previous paper [19]. Briefly, air-dried roots of O. elatus $(4 \mathrm{~kg})$ were extracted with refluxing $95 \%$ ethanol $(28 \mathrm{~L})$ three times for $5 \mathrm{~h}$ each. The ethanol extracts were combined and concentrated and the residue was suspended in distilled water. The solution was then partitioned with ethyl acetate. The ethyl acetate fraction was fractionated by column chromatography on silica gel eluted with a gradient of petroleum ether-ethyl acetate (99:1,95:5). The 95:5 eluent was collected and concentrated under vacuum to give $67 \mathrm{~g}$ of residue, which was used as the polyynes extract of $O$. elatus.

To characterize the chemical constituents in PEO, a UPLC-QTOF-MS/MS method was established (Supplement I2). The total ion chromatograms in positive ion modes were displayed in Figure S2A. The UPLC chromatogram of PEO extract recorded at $203 \mathrm{~nm}$ is shown in Figure S2B. In Table S1, a total of nine components were detected, and two of those (FAD and OPD) were identified by comparing their retention times, mass accuracy, and fragmentation behaviors with data from the corresponding references [30,31].

The determination of FAD and OPD in the PEO was performed by HPLC-ELSD (Figure 5A). The structures of the determined polyynes are shown in Figure 5B. The percentages of facarindiol and oplopandiol were $24.39 \%$ and $57.90 \%$ [19]. 
A

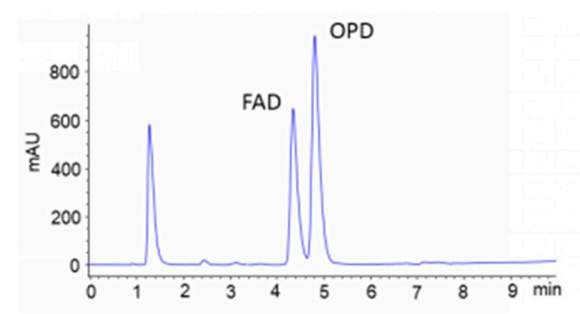

B

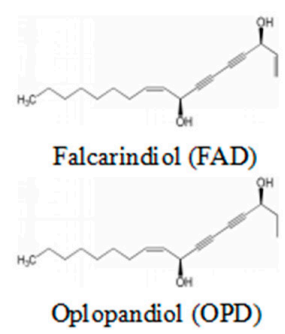

C

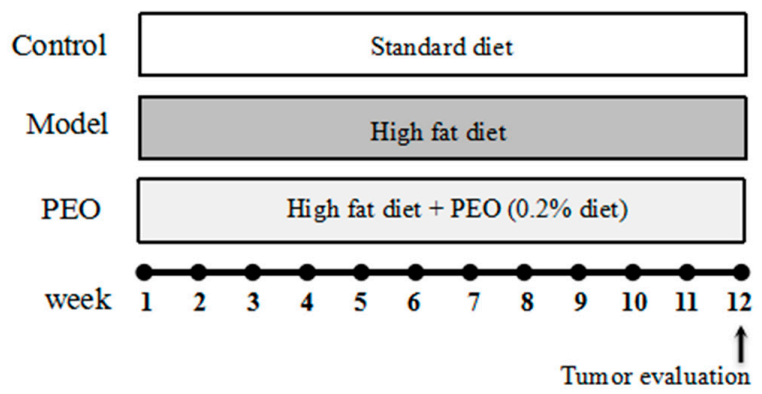

Figure 5. Chemical structures and HPLC analysis of polyynes in PEO extract. HPLC chromatogram of PEO extract recorded at $203 \mathrm{~nm}$ is shown in (A); Two polyynes in PEO extract were determined: falcarindiol (FAD) and oplopandiol (OPD). The structures of the determined polyynes are shown in (B); The percentages of FAD and OPD in PEO extract were $24.39 \%$ and $57.90 \%$, respectively. The animal experimental protocol is shown in $(\mathbf{C})$.

\subsection{Animal Studies}

All procedures described involving animals were performed on the basis of protocols approved by the Institutional Animal Care and Use Committee at the China Pharmaceutical University. Sixteen male C57BL/6J-Apc Min/+ mice and eight wild-type mice were obtained at 6 weeks of age from the Model Animal Research Center of Nanjing University. Animals were maintained in a temperature and humidity controlled facility with 12-h light/dark cycles in the Center for New Drug Safty Evaluation and Research.

All animals were allowed a seven-day acclimation period prior to being randomly assigned to a model $(n=8)$ or PEO group $(n=8)$. The wild-type mice were used as controls $(n=8)$ fed with normal diet (Xietong Organism, Nanjing, China). The model group was fed with high fat diet, while the PEO group was fed with high fat diet supplemented with PEO (0.2\% diet, Xietong Organism, Nanjing, China) for 12 weeks. The high-fat diet was composed of protein $13 \%$, carbohydrate $47.6 \%$ and fat $39.4 \%$ (of total energy, \% kcal, Table S2). One mouse ate about $3 \mathrm{~g}$ diet a day. Thus, the PEO oral administration is about $6 \mathrm{mg}$ per mouse a day. The experimental protocol is shown in Figure 5C. The animals were weighed daily throughout the experimental period. The minimal stool bleeding score was 0 , and the maximal score was 4 ( 0 , none; 1 , trace; 2 , mild hemoccult; 3 , obvious hemoccult; 4 , gross bleeding), which was detected by Hemoccult Sensa test strips (Beckman, Brea, CA, USA). At the end of 12 weeks, blood was collected from retinal venous plexus, centrifuged and the serum was harvested and stored at $-80^{\circ} \mathrm{C}$. Then, mice were sacrificed by cervical dislocation. The whole intestine was removed immediately after sacrifice and opened longitudinally after washed with ice-cold PBS. The small intestine was cut into three equal parts, namely S1, S2, S3 and the large intestine (C) consisted of cecum and colon. The number, location, and size of visible tumors throughout the intestine were measured to calculate the incidence of adenoma. The total diameter of all the tumors per mouse was named tumor burden. About $1 \mathrm{~cm}$ segments from the S1, S2, S3 and C were taken, fixed in $10 \%$ phosphate-buffered formalin for $24 \mathrm{~h}$ for hematoxylin and eosin staining and immunohistochemistry analyses. The remaining tissues were kept frozen at $-80^{\circ} \mathrm{C}$. 


\subsection{Western Blotting}

Harvested colon tissues or cultured cell pellets were homogenized and lysed in ice-cold RIPA lysis buffer (P0013B, Beyotime, Nanjing, Jiangsu, China). Protein concentration was determined using a Bicinchoninic Acid Protein Assay kit (P0010S, Beyotime). These protein were electrophoresed in 10\% SDS-PAGE gels and transferred to a polyvinylidene difluoride membrane (PVDF, Millipore, Billerica, MA, USA). The membranes were blocked with $5 \%$ fat-free milk and incubated with different primary antibodies. The bound antibodies were detected using horseradish peroxidase-conjugated goat anti-rabbit IgG (H + L) (1:1000; KGAA35, Keygen, Nanjing, China) or goat anti-mouse IgG (H + L) (1:2000; KGAA35, Keygen). The PVDF membranes were subsequently subjected to immunoblotting analysis using the enhanced chemiluminescence (ECL, Tanon, Shanghai, China) according to the manufacturer's protocol on Luminescent Image Analyzer Tanon5200 (Tanon). Finally, blots were quantified using the Tanon Image Analysis System.

\subsection{Histology and Immunohistochemistry}

In an ice bath, small intestine and colon were dissected to obtain tumor and para-tumor tissues. These tissues were fixed in 10\% phosphate-buffered formalin, dehydrated, paraffin-embedded, characterized with hematoxylin-eosin staining and analyzed by pathology professionals. The immunohistochemistry were carried out as previously described [32]. The antibodies used in this study were anti- $\beta$-catenin for immunohistochemistry.

\subsection{Cell Culture and Treatment}

HCT116 and SW480 human colon cancer cell lines were purchased from the Cell Bank of the Chinese Academy of Sciences (Shanghai, China) and KeyGen Biotech (Nanjing, China), separately. Both lines were maintained at $37^{\circ} \mathrm{C}$ in an atmosphere containing $5 \% \mathrm{CO}_{2}$ in Dulbecco's modified Eagle's medium (DMEM, Keygen, Nanjing, China) supplemented with $10 \%(v / v)$ fetal bovine serum (FBS, Gibco, SA). Cells were seeded in 10-cm dish at the density of $1 \times 10^{5}$ cells / dish for $24 \mathrm{~h}$, then treated with either $0.1 \%$ DMSO, or different concentrations of PEO for $24 \mathrm{~h}$.

\subsection{MTT Assay}

The cells in the logarithmic phase, between $5 \times 10^{3}$ and $10 \times 10^{3}$ in $100 \mu \mathrm{L}$, were seeded in 96-well plate. After $24 \mathrm{~h}$, the cells were treated with various concentrations of PEO ranging from $1 \mu \mathrm{M}$ to $25 \mu \mathrm{M}$. After $24 \mathrm{~h}$ of incubation at $37^{\circ} \mathrm{C}$ in $5 \% \mathrm{CO}_{2}$, the supernatant was removed and replaced by $100 \mu \mathrm{L}$ of 1, 5, 10, $25 \mu \mathrm{M}$ PEO for 24 h. $20 \mu \mathrm{L}$ of 3-(4,5-dimethylthiazol-2-yl)-2,5-diphenyltetrazolium bromide (MTT, Sigma, Louis, MO, USA) solution was added to each plate and incubation was performed at $37^{\circ} \mathrm{C}$ for $4 \mathrm{~h}$. Medium was removed, and $100 \mu \mathrm{L}$ dimethyl sulphoxide (DMSO, Hanbang, Jiangsu, China) was added to dissolved the purple crystals of formazan and incubated for $30 \mathrm{~min}$ at $37^{\circ} \mathrm{C}$ constant temperature oscillator (THZ-C, Taicang, Jiangsu, China). Finally, the optical density (OD) was measured at $490 \mathrm{~nm}$ using a Microplate Reader (51119000, Thermo, Waltham, MA, USA). Cell viability was calculated using the following formula:

$$
\text { Cell viability } \%=\left[\left(\mathrm{OD}_{\text {drug }}-\mathrm{OD}_{\text {zero }}\right) /\left(\mathrm{OD}_{\text {control }}-\mathrm{OD}_{\text {zero }}\right)\right] \times 100 \%
$$

\subsection{Q-PCR}

HCT116 cells were seeded at $1 \times 10^{6}$ cells / well in 6-well-plates and cultured overnight. Then, the cells were respectively treated with various concentrations of PEO $(0,1,5,25 \mu \mathrm{M})$ for $24 \mathrm{~h}$. The total RNA was isolated using Trizol reagent (Thermo) following the supplier's instruction. The cDNA was synthesized from total RNA using HiScript ${ }^{\circledR}$ II 1st Strand cDNA Synthesis Kit (Vazyme, Nanjing, Jiangsu, China) according to the manufacturer's instructions. RT-PCR analyses were performed on the Applied Biosystems QuantStudio 3 Real-Time PCR Systems (Thermo) using ChamQ ${ }^{\mathrm{TM}} \mathrm{SYBR}^{\circledR}$ 
qPCR Master Mix (Vazyme). The cDNA was amplified with the following primers: c-myc forward, 5'-CTG AGG AGG AAC AAG AAG ATG AG-3'; c-myc reverse, 5'-TGT GAG GAG GTT TGC TGT G-3'; cyclinD1 forward, $5^{\prime}$-GGT TCA ACC CAC AGC TAC TT-3'; cyclinD1 reverse, $5^{\prime}$-CAG CGC TAT TTC CTA CAC CTA TT-3'; $\beta$-catenin forward, $5^{\prime}$-CAT CTA CAC AGT TTG ATG CTG CT-3'; $\beta$-catenin reverse, 5'-GCA GTT TTG TCA GTT CAG GGA-3'; Glyceraldehyde 3-phosphate dehydrogenase (GAPDH) forward, 5' -GGT GTG AAC CAT GAG AAG TAT GA-3'; GAPDH reverse, $5^{\prime}$-GAG TCC TTC CAC GAT ACC AAA G-3'. The PCR amplifications were performed at $95^{\circ} \mathrm{C}$ for $30 \mathrm{~s}$, followed by 40 cycles of thermal cycling at $95^{\circ} \mathrm{C}$ for $10 \mathrm{~s}$, and $60^{\circ} \mathrm{C}$ for $30 \mathrm{~s}$. All the qPCR analyses were performed in triplicate. Finally, the cycle threshold $\left(\mathrm{C}_{\mathrm{T}}\right)$ values were determined for analysis.

\subsection{Statistics}

Statistical analysis was performed using Prism 5.0 software (GraphPad Inc., La Jolla, CA, USA). Each analyzed parameter was expressed as Mean \pm SE. The statistical significance of the differences was determined using one-way analysis of variance and Tukey's multiple comparison test. $p<0.05$ was considered statistically significant $\left({ }^{*} p<0.05 ;{ }^{* *} p<0.01 ;{ }^{* * *}, p<0.001\right)$.

Supplementary Materials: Supplementary materials are available online.

Acknowledgments: This work was supported by the National Natural Science Foundation of China (Grant No. 81373957, 81573567 and 81373919) and the Jiangsu "Shuang Chuang" team.

Author Contributions: Jie Yang, Chunsu Yuan and Ping Li conceived and designed the experiments; Xiaodong Wen, Wei Sun, Xin Qiao and Chongzhi Wang performed the experiments; Li Zhang assisted in part of the research; Xin Qiao analyzed the data and wrote the paper.

Conflicts of Interest: The authors declare no conflict of interest.

\section{References}

1. Favoriti, P.; Carbone, G.; Greco, M.; Pirozzi, F.; Pirozzi, R.E.; Corcione, F. Worldwide burden of colorectal cancer: A review. Updates Surg. 2016, 68, 7-11. [CrossRef] [PubMed]

2. Siegel, R.L.; Miller, K.D.; Jemal, A. Cancer statistics, 2017. Cancer J. Clin. 2017, 67, 7-30. [CrossRef] [PubMed]

3. Dorudi, S.; Steele, R.J.; McArdle, C.S. Surgery for colorectal cancer. Br. Med. Bull. 2002, 64, 101-118. [CrossRef] [PubMed]

4. Park, H.C.; Choi, D.H. Radiation therapy for colorectal cancer. J. Korean Med. Assoc. 2010, 53, 592-602. [CrossRef]

5. Moertel, C.G. Chemotherapy for colorectal cancer. N. Engl. J. Med. 1994, 330, 1136-1142. [CrossRef] [PubMed]

6. Koido, S.; Ohkusa, T.; Homma, S.; Namiki, Y.; Takakura, K.; Saito, K.; Ito, Z.; Kobayashi, H.; Kajihara, M.; Uchiyama, K.; et al. Immunotherapy for colorectal cancer. World J. Gastroenterol. 2013, 19, 8531-8542. [CrossRef] [PubMed]

7. Loree, J.M.; Kopetz, S. Recent developments in the treatment of metastatic colorectal cancer. Ther. Adv. Med. Oncol. 2017, 9, 551-564. [CrossRef] [PubMed]

8. Atanasov, A.G.; Waltenberger, B.; Pferschy-Wenzig, E.M.; Linder, T.; Wawrosch, C.; Uhrin, P.; Temml, V.; Wang, L.; Schwaiger, S.; Heiss, E.H.; et al. Discovery and resupply of pharmacologically active plant-derived natural products: A review. Biotechnol. Adv. 2015, 33, 1582-1614. [CrossRef] [PubMed]

9. Ma, W.K.; Li, H.; Dong, C.L.; He, X.; Guo, C.R.; Zhang, C.F.; Yu, C.H.; Wang, C.Z.; Yuan, C.S. Palmatine from Mahonia bealei attenuates gut tumorigenesis in $a p c^{\mathrm{min} /+}$ mice via inhibition of inflammatory cytokines. Mol. Med. Rep. 2016, 14, 491-498. [CrossRef] [PubMed]

10. Yang, J.C.; Hwang, H.S.; Lee, H.J.; Jung, S.Y.; Ji, S.J.; Oh, S.H.; Lee, Y.M. Distribution of vascular plants along the altitudinal gradient of Gyebangsan (mt.) in Korea. J. Asia Pac. Biodivers. 2014, 7, e40-e71. [CrossRef] 
11. Moon, H.K.; Kim, J.A.; Park, S.Y.; Kim, Y.W.; Kang, H.D. Somatic embryogenesis and plantlet formation from a rare and endangered tree species, Oplopanax elatus. J. Plant Biol. 2006, 49, 320-325. [CrossRef]

12. Calway, T.; Du, G.J.; Wang, C.Z.; Huang, W.H.; Zhao, J.; Li, S.P.; Yuan, C.S. Chemical and pharmacological studies of Oplopanax horridus, a north American botanical. J. Nat. Med. 2012, 66, 249-256. [CrossRef] [PubMed]

13. Shikov, A.N.; Pozharitskaya, O.N.; Makarov, V.G.; Yang, W.Z.; Guo, D.A. Oplopanaxelatus elatus (nakai) nakai: Chemistry, traditional use and pharmacology. Chin. J. Nat. Med. 2014, 12, 721-729. [CrossRef] [PubMed]

14. Eom, S.H.; Lee, J.K.; Kim, H.; Hyun, T.K. De novo transcriptomic analysis to reveal functional genes involved in triterpenoid saponin biosynthesis in Oplopanax elatus nakai. J. Appl. Bot. Food Qual. 2017, 90, 18-27. [CrossRef]

15. Shikov, A.N.; Pozharitskaya, O.N.; Makarov, V.G. Aralia elata var. Mandshurica (rupr. \& maxim.) j.Wen: An overview of pharmacological studies. Phytomedicine 2016, 23, 1409-1421. [CrossRef] [PubMed]

16. Huang, W.H.; Zhang, Q.W.; Yuan, C.S.; Wang, C.Z.; Li, S.P.; Zhou, H.H. Chemical constituents of the plants from the genus Oplopanax. Chem. Biodivers. 2014, 11, 181-196. [CrossRef] [PubMed]

17. Wang, C.Z.; Zhang, Z.; Huang, W.H.; Du, G.J.; Wen, X.D.; Calway, T.; Yu, C.; Nass, R.; Zhao, J.; Du, W.; et al. Identification of potential anticancer compounds from Oplopanax horridus. Phytomedicine 2013, 20, 999-1006. [CrossRef] [PubMed]

18. Jin, H.R.; Zhao, J.; Zhang, Z.; Liao, Y.; Wang, C.Z.; Huang, W.H.; Li, S.P.; He, T.C.; Yuan, C.S.; Du, W. The antitumor natural compound falcarindiol promotes cancer cell death by inducing endoplasmic reticulum stress. Cell Death Dis. 2012, 3, e376. [CrossRef] [PubMed]

19. Sun, W.; He, Y.S.; Xu, L.H.; Zhang, B.Y.; Qi, L.W.; Yang, J.; Li, P.; Wen, X.D. Pharmacokinetic profiles of falcarindiol and oplopandiol in rats after oral administration of polyynes extract of Oplopanax elatus. Chin. J. Nat. Med. 2016, 14, 714-720. [CrossRef]

20. Cao, H.; Song, S.; Zhang, H.; Zhang, Y.; Qu, R.; Yang, B.; Jing, Y.; Hu, T.; Yan, F.; Wang, B. Chemopreventive effects of berberine on intestinal tumor development in Apc ${ }^{\mathrm{min} /+}$ mice. BMC Gastroenterol. 2013, 13, 163. [CrossRef] [PubMed]

21. Chang, Y.C.; Chang, J.G.; Liu, C.Y.; Yang, S.F.; Ho, C.M.; Chen, W.T.L.; Chang, Y.S. Mutation analysis of 13 driver genes of colorectal cancer-related pathways in Taiwanese patients. World J. Gastroenterol. 2016, 22, 2314-2325. [CrossRef] [PubMed]

22. Zhang, S.C.; Wang, K.Z. The effect of Echinopanax elatum Nakai on experimental arthritis and the neuro-hypophyseal-adrenal system. Acta Pharm. Sin. 1980, 2, 81-85. [CrossRef]

23. Kown, H.S.; Kim, D.H.; Shin, H.K.; Yu, C.Y.; Kim, M.J.; Lim, J.D.; Park, J.K.; Kim, J.K. Fourteen-day repeated-dose oral toxicity study of the ethanol extracts isolated from Oplopanax elatus in Sprague-Dawley rat. Korean J. Food Sci. Technol. 2007, 39, 470-475.

24. Rao, T.P.; Kuhl, M. An updated overview on Wnt signaling pathways: A prelude for more. Circ. Res. 2010, 106, 1798-1806. [CrossRef] [PubMed]

25. Clevers, H.; Nusse, R. Wnt/ $\beta$-catenin signaling and disease. Cell 2012, 149, 1192-1205. [CrossRef] [PubMed]

26. Polakis, P. Wnt signaling and cancer. Genes Dev. 2000, 14, 1837-1851. [CrossRef] [PubMed]

27. Moon, R.T. The Wnt/ $\beta$-catenin pathway. Sci. Signal. 2003, 2003, 271. [CrossRef]

28. Fodde, R. The Apc gene in colorectal cancer. Eur. J. Cancer 2002, 38, 867-871. [CrossRef]

29. Mármol, I.; Sánchezde, D.C.; Pradilla, D.A.; Cerrada, E.; Rodriguez, Y.M.J. Colorectal Carcinoma: A General Overview and Future Perspectives in Colorectal Cancer. Int. J. Mol. Sci. 2017, 18, 197. [CrossRef] [PubMed]

30. Purup, S.; Larsen, E.; Christensen, L.P. Differential effects of Falcarinol and related aliphatic C(17)-polyacetylenes on intestinal cell proliferation. J. Agric. Food Chem. 2009, 57, 8290-8296. [CrossRef] [PubMed]

31. Shao, L.; Nie, M.K.; Chen, M.Y.; Wang, J.; Wang, C.Z.; Huang, W.H.; Yuan, C.S.; Zhou, H.H. Screening and identifying antioxidants from Oplopanax elatus using 2,2'-diphenyl-1-picrylhydrazyl with off-line two-dimensional HPLC coupled with diode array detection and tandem time-of-flight mass spectrometry. J. Sep. Sci. 2016, 39, 4269-4280. [CrossRef] [PubMed] 
32. Wen, X.D.; Wang, C.Z.; Yu, C.; Zhao, L.; Zhang, Z.; Matin, A.; Wang, Y.; Li, P.; Xiao, S.Y.; Du, W.; et al. Panax notoginseng attenuates experimental colitis in the azoxymethane/dextran sulfate sodium mouse model. Phytother. Res. 2014, 28, 892-898. [CrossRef] [PubMed]

Sample Availability: Samples of the compound PEO is available from the authors.

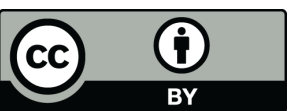

(C) 2017 by the authors. Licensee MDPI, Basel, Switzerland. This article is an open access article distributed under the terms and conditions of the Creative Commons Attribution (CC BY) license (http:/ / creativecommons.org/licenses/by/4.0/). 